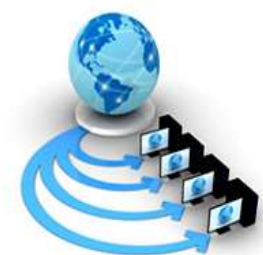

Volume 9, No. 5, September-October 2018

International Journal of Advanced Research in Computer Science

REVIEW ARTICLE

Available Online at www.ijarcs.info

\title{
ROBUST AND AUTOMATED LUNG CANCER NODULE DETECTION USING IMAGE PROCESSING TECHNIQUES
}

\author{
M. Prem Chander \\ Ph.D. Research Scholar, Dept. CSE, GITAM UNIVERSITY, Vishakhapatnam, India. \\ Dr. M. Venkateshwara Rao \\ Associate Professor, Dept. IT, GITAM UNIVERSITY, Vishakhapatnam, India. \\ Dr. T. V. Rajini Kanth \\ Professor, Dept. CSE, Sreenidhi Institute of Science and Technology, Hyderabad, India.
}

\begin{abstract}
In the medical field among all the types of cancers, lung cancer is more serious disease. Detection of lung cancer in the beginning will recover the lifetime of the patient. Using image processing techniques, Computed tomography scan images are very useful to find lung cancer nodule. The image pre-processing methods are feature extraction, image enhancement and image segmentation. Watershed transformation and based on Gabor filter to find lung cancer nodule. This research paper aim is to find more precise results using different segmentation and enhancement techniques.
\end{abstract}

Keywords: Image processing, Watershed transformation, Gabor filter, Lung cancer.

\section{INTRODUCTION}

The main purpose of medical image analysis is to detect lung cancer using meaningful information to support disease diagnosis and therapy. Accuracy and quality are two factors of the image, image enhancement and segmentation principles used in pre-processing to get feature extraction in the following steps: 1. Cigarette smoking cases of the male are $85 \%$ and the female are $75 \%$ [1]-[2]. 2. Gabor filter and watershed transform are more useful to remove the noise. 3. As shown in figure 1 explains the theory of the various steps in the pre- processing stage. 4. The patient life span can be increased at the early stage of the cancer. Al Taraweeh et al [3] explained the image enhancement methods strongly depends on statistical operations and subjective observation such as variance and mean calculation. Sami et al [4] has presented that lung disease scan images are used to find the lung cancer. Ajil et al[5] described CT images are more sensitive in finding the tumor size and the lymph nodes of the lung.

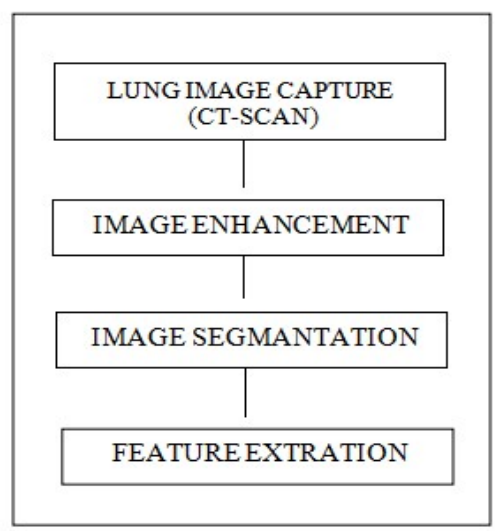

Figure. 1:- Lung cancer detection system architecture diagram

\section{I.I Image Enhancement}

Chaudary et al.[7]-[8] explained with image enhancement by the focus to improve the sensitivity, quality, and interpretability in an image pre-processing stage.

The image enhancement methods are given below.

- Noise removal using a wiener filter

- Median filtering

- Filtering with morphological operators

- Histogram equalization

The quality of computed tomography images can be improved by the transform coefficient functions. The image enhancements benefits are as follows:

- Frequency domain

- Computations of Complexity

- Frequency coefficient of an image manipulation

- Domain purpose improvement.

Xiuhua et al.[6] explained early diagnosis and better treatment can save a life, lung cancer is more critical and life taking disease in the world.

\section{I.II Equalization of histogram}

Histogram equalization is a process of contrast enhancement, as explained a framework technique is used in histogram modification. The distributed histogram is obtained by cumulative distribution function, in the input image.

\section{I.II Segmentation of image}

Partition of a prototype into equivalent measure of component part in which to each one picture element holding with as is attributes. These partitioned images are meaningful and useful information. The first step of the 
image from low-level image processing into more other images such as objects and features, an accurate partitioning of an image in the image segmentation is a challenging problem [10]-[11].

Application areas of image segmentation are mentioned below.

- Pattern Recognition

- Image Encryption

- Image Processing

- Medical and Biomedical imaging

- Computer Graphics

- Computer Vision

I.IV Thresholding.

It is a process of segmenting the image into equal parts, by separating of light and dark pixels. If $A(i, j)$ is a threshold version of $B(i, j)$ at some global threshold $T$. $A=1$ if when $\mathrm{B}(\mathrm{i}, \mathrm{j}) \geq \mathrm{T}$.

Huang et al. [13] explained about thresholding technique is based on the similarity in textural features.

\section{V Feature Extraction}

In image processing techniques feature extraction is a part of thresholding, resizing linearization, and normalization. Feature extraction techniques used in image recognition and classification as character recognition.

\section{PROPOSED METHODOLOGY}

Rendon and gonzalez et al. [12] and [14] lung cancer detection is having four steps:

- Enhancement.

- Feature extraction.

- Segmentation and

- Nodule detection.

The proposed methodology includes pre-processing of the images to extract the features of lung cancer in an automated process and subjected to the following steps.

- The pre-processing stage that improves the nature of the picture by evacuating the undesirable noise to feature the malignant information.

The feature extraction acquires the discrete components of the image under processing.

- The classification stage identifies the objects of an image according to certain classes and helps in recognition of efficient data.

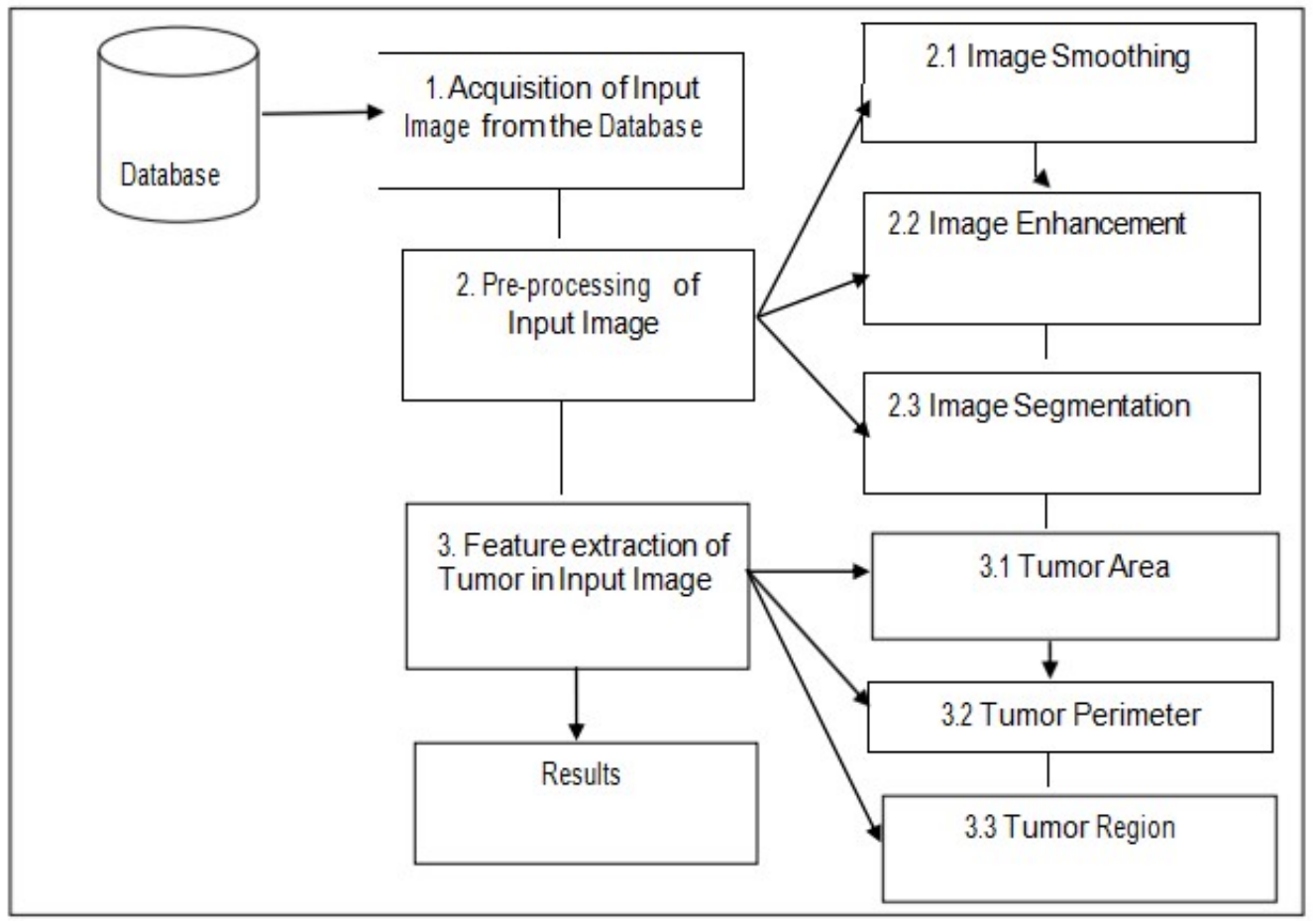

Figure. 2:-Different types of techniques for identifying lung cancer.

\section{II .I Pre-processing}

Smoothing is a process of image processing technique to remove noise and fluctuations in the image. To remove the image noise, reduce salt and pepper noise by using median filter. Ruchika et al.[9] explained about an image smoothing in the image pre-processing stage. The smoothing process is also used for detection of lung cancer nodule and in reduction of noise from the computed tomography images.

\section{II.II Feature extraction}

As shown in figure.2, a flowchart which explains various steps while detecting the malicious node, from various CT scan images.

A) Area of the nodule:

Area $=($ Axy, IROI $[$ AREA $]=x, J$ ROI $[$ Area $]=y)$ Where $x \& y$ are the pixels. 
B) The array of edge that contains at least one value, among 0 to 255 values

created by transformation function. Perimeter of the nodule:

$\mathrm{P}=(\mathrm{Pxy}, \mathrm{I}$ edge $[\mathrm{P}]=\mathrm{x}, \mathrm{J}$ edge $[\mathrm{P}]=\mathrm{y})$

Where $\mathrm{I}$ and $\mathrm{J}$ are vectors, $\mathrm{x} \& \mathrm{y}$ are the pixels.

C) Eccentricity: Eccentricity is used to measure the region of tumor (I). If it is

circular I value is 1 , otherwise $<1$. (I) $=$ major axis $/$ minor axis

\section{RESULTS AND DISCUSSION}

Detection of cancer using image processing techniques, lung cancer stages are involved in the practical situation of cancer which transforms from the human body to various parts [15]-[16]. The smallest lung cancer nodule sizes are all between $5 \mathrm{~mm}$ and $25 \mathrm{~mm}$ [17]-[18].

Wang $J$ et al.[22] computed tomography(CT) and Computer-aided diagnosis(CAD) schemes for thoracic are widely used to detect lung abnormalities. Threshold value is verified after the edge of the lung boundary is matched [19]-[21] and [25].

For more details of lung cancer detection by using based on Gabor filter and watershed segmentation, see [23], [24], [26], [27] and [28]. And also knows that the presence or absence of cancer in lymph nodes.

As shown in Fig. 3, the lung cancer nodule image is shown in the above diagrams. For more details of image enhancement and feature extraction, see [29], [30], [31], [32], [33] and [34].

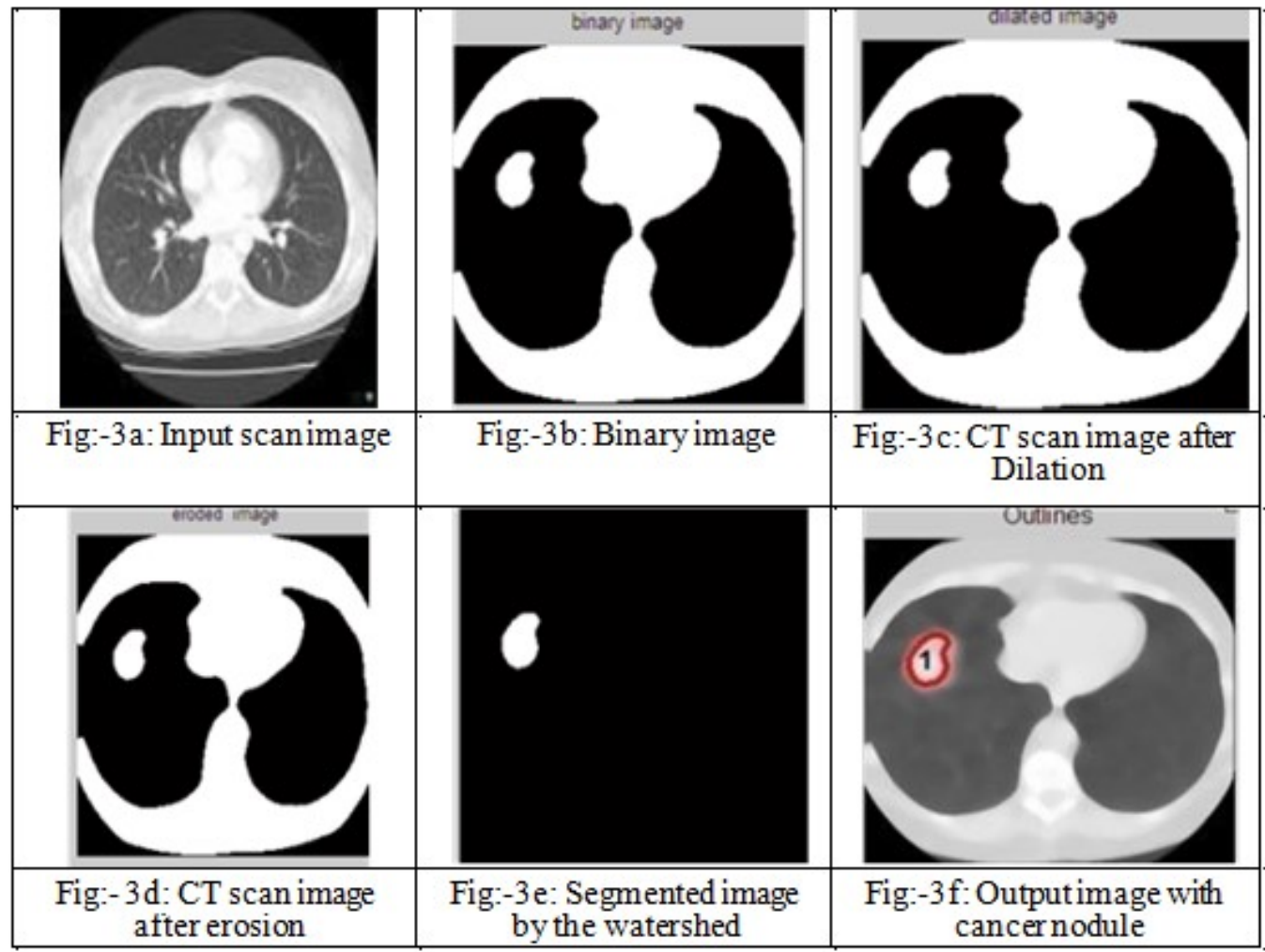

Figure 3

\section{CONCLUSION}

The lung cancer detection system has been developed successfully. Lung cancer is the most critical disease which grows cancer cells in the abnormal way. The various image processing techniques are mostly useful in the medical areas. Computed tomography scan images are very useful for finding the lung tumor, based on the Gabor filter and various types of image segmentation techniques are used to detect the lung cancer. So this proposed method is highly suitable for identification of perimeter, eccentricity and area of the lung cancer tumor, according to this information diagnosis will be given by the physicians.

\section{ACKNOWLEDGEMENTS}

The research was supported by Dr. M. Venkateshwara Rao, and Dr. T. V. Rajini Kanth, For their valuable guidance for this paper.

\section{REFERENCES}

[1] M. Premchander, Dr.T. V. Rajinikanth, and Dr. M . Venkateshwara Rao, "Detection of Lung Cancerin Medical ImagesUsing Image Processing Techniques "International Journal of Emerging Technology and 
Advanced Engineering (ISSN 2250-2459, ISO 9001:2008 Certified Journal, Volume 7, Issue 7, July 2017).

[2] M. Premchander, Dr.T. V. Rajinikanth, and Dr. M . Venkateshwara Rao "'Detection of Lung Cancer Using Digital Image Processing Techniques: A Comparative Study" International Journal of Medical Imaging, 2017; 5(5): 58-62,doi: 10.11648/j.ijmi.20170505.12, ISSN: 2330-8303 (Print); ISSN: 2330-832X (Online).

[3] Al Tarawneh MS. Lung cancer detection using image processing techniques. Leonardo Electronic Journal of Practices and Technologies. 2012.

[4] Gindi,A. M., Al Attiatalla, T. A., \& Sami, M.M. "A Comparative Study for Comparing Two Feature Extraction Methods and Two Classifiers in Classification of Early stage Lung Cancer Diagnosis of chest x-ray images." Journal of American Science, 2014.

[5] Ajil MV, Sreeram S. Lung cancer detection from CT images using various image processing techniques. International Journal of Advance Research in Computer Science and Management Studies.2015 May; 3(5), 24954.

[6] Xiuhua,G., Tao, S., \&Zhigang, L, "Prediction Models for Malignant Pulmonary Nodules Based-on Texture Features of CT Image." In Theory and Applications of CT Imaging and Analysis. 2011.

[7] Chaudhary A, Singh SS. Lung cancer detection on CT images by using image processing. International Conference on Computing Science, Phagwara. 2012.

[8] Goswami A. For image enhancement and segmentation by using evaluation of gabor filter parameters. International Journal of Advanced Technology and Engineering Research. 2012.

[9] Ruchika Kalra A. Detection of lung cancer in CT images using mean shift algorithm. International Journal of Advanced Research in Computer Science and Software Engineering. 2015.

[10] Roy, T., Sirohi, N., \&Patle, A. (2015) "Classification of lung image and nodule detection using fuzzy inference system." International Conference On Computing, Communication \& Automation., 2015.

[11] Ignatious, S., \& Joseph, R. (2015) "Computer aided lung cancer detection system.” 2015 Global Conference On Communication Technologies (GCCT).

[12] Rendon-Gonzalez， E., \&Ponomaryov， V. (2016) "Automatic Lung nodule segmentation and classification in CT images based on SVM." 2016 9Th International Kharkiv Symposium On Physics And Engineering Of Microwaves, Millimeter And Submillimeter Waves (MSMW).

[13] Ng HP, Huang S, Ong SH, Foong KWC, Goh PS, Nowinski WL. Medical image segmentation using watershedsegmentation with texture merging. IEEE Engineering in medicine and biology Society Conference, Canada. 2008.

[14] Patela SVK, Shrivastavab P. Implementation of medical image enhancement technique using gabor filter. International Journal of Current Engineering and Technology. 2012.

[15] Tanaka K, Sakuma T. Geographical difference of chromosome aberrations between Japanese and American small cell lung cancer cell lines. Indian Journal of Science and Technology. 2012.

[16] SPIE-AAPM-NCI Lung Nodule Classification
Challenge Dataset. The Cancer Imaging Archive; 2015.

[17]Hollings N., Shaw P. Diagnostic imaging of lung cancer. European Respiratory Journal. 2002.

[18] Li W., Nie S. D., Cheng J.Berlin, A fast automatic method of lung segmentation in CT images using mathematical morphology; pp. 2419-2422. (IFMBE Proceedings) Springer; 2007.

[19] Hu S., Hoffman E. A., Reinhardt J. M. Automatic lung segmentation for accurate quantitation of volumetric X-ray CT images. IEEE Transactions on Medical imaging, 2001.

[20] Shah S. Automatic cell images segmentation using a shape-classification model. IEICE Transactions on Information and Systems. 2007.

[21] Prasad M. N., Brown M. S., Ahmad S., et al. Automatic segmentation of lung parenchyma in the presence of diseases based on curvature of ribs. Academic Radiology. 2008.

[22] Wang J., Li F., Li Q. Automated segmentation of lungs with severe interstitial lung disease in CT. Medical Physics. 2009.

[23] Armato S., MacMahon H. Automated lung segmentation and computer-aided diagnosis for thoracic CT scans. Internationa 1 Congress Series. 2003.

[24] Sudha V, Jayashree P. Lung Nodule Detection in CT Images Using Thresholding and Morphological Operations. International Journal of Emerging Science and Engineering. 2012.

[25]Guo Y., Feng Y., Sun J., et al. Automatic lung tumor segmentation on PET/CT images using fuzzy markov random field model. Computational and Mathematical Methods in Medicine. 2014.

[26] Lam M., Disney T., Pham M., Raicu D., Furst J., Susomboon R. Content-based image retrieval for pulmonary computed tomography nodule images. Medical Imaging 2007: PACS and Imaging Informatics; March 2007.

[27] Dhara A. K., Chama C. K., Mukhopadhyay S., Khandelwal N. Content-based image retrieval system for differential diagnosis of lung cancer. Indian Journal of Medical Informatics. 2012.

[28] Nirmala J. B., Gowri S. A content based CT lung image retrieval by DCT matrix and feature vector technique. International Journal of Computer Science Issues. 2012.

[29] Huang Q, Gao W, Cai W. Thresholding technique with adaptive window selection for uneven lighting image. Pattern Recognition Letters. 2005 May.

[30]Liu C.-T., Tai P.-L., Chen A. Y.-J., Peng C.-H., Lee T., Wang J.-S. A content-based CT lung image retrieval system for assisting differential diagnosis images collection. Proceedings of the IEEE International Conference on Multimedia and Expo (ICME 2001), 2001.

[31] Nguyen worring HT, Van de Boomgaard R. Watersnakes: Energy-driven watershed segmentation. Pattern Analysis and Machine Intelligence. 2003.

[32]Patil S. A., Kuchanur M. B. Lung cancer classification using image processing. International Journal of Engineerin and Innovative Technology. 2012. 
[33] A. patil and M. B Kuchanur, "Lung cancer classification using image processing", International Journal of Engineering and Innovative Technology, vol. 2, no. 3, 2012.

[34] J. Kuruvilla and K. Gunavathi, "Lung cancer classification using neural networks for CT images", Computer Methods and Programs in Biomedicine, vol. 113, no. 1, pp. 202-209, 2014.

\section{AUTHOR'S BIOGRAPHY}

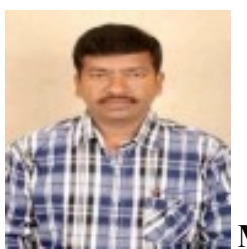

M. Prem Chander has been pursuing Ph. D degree in Computer Science and Engineering from GITAM UNIVERSITY, Visakhapatnam, A.P India, as well as working as Asst. Professor of CSE Department in MNR College of Engineering and Technology, Hyderabad. As well as obtained M. Tech. in Computer Science and Engineering from Jawaharlal Nehru Technological University(JNTU), Anantapurum, AP, INDIA in 2011. Prior to his professional career, he obtained Bachelor of Technology (B. Tech) in Computer Science and Information Technology from Sri Datta Institute of Engineering and Science, Hyderabad, Affiliated to JNTUH Hyderabad, Telangana, India in 2005. His current research interests include Image Processing and Data Warehousing \& Mining for Medical Applications. His total teaching experience is 13 years. He guided around 30 projects at B. Tech. and 10 projects at M. Tech. level. He has conducted two national Conferences namely CONVIVALITY 2K11, and CONVIVALITY 2K12 at MEC, Hyderabad as Convener. He is a Member in IEEE.


$\mathrm{Ph}$. D degree in C.S.E branch. He is working as Associate Professor in the Department of Information Technology, in Gitam Institute of Technology, GITAM UNIVERSITY, Visakhapatnam, $\mathrm{AP}$, and India. $\mathrm{He}$ obtained his $\mathrm{M}$. Sc(Electronics), M. Phil (Opto Electronics), and M. Tech(CST). His teaching and Industrial experience is
25 years. His writings have appeared in numerous Professional conferences and Journals (International journals-5 National conferences-2.

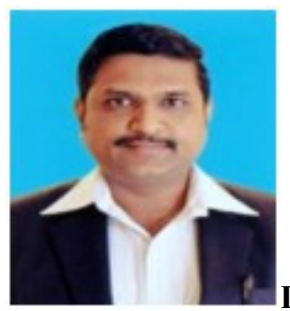

Dr. T. V. Rajini Kanth has obtained his Ph.D. degree in C.S.E. branch from Osmania university, Hyderabad in July, 2008 and M. Tech.(C.S.E.) degree from Osmania University, Hyderabad in January, 2001. His specialization area in research is "Spatial Data mining". He obtained his PGDCS degree from HCU, Hyderabad in 1996. He received his M. Sc. (Applied mathematics) degree in the year 1989 from S.V. University, Tirupati as University Ranker. He is currently working as professor in CSE, at SNIST, Hyderabad. He worked as a Professor and Head, Department of IT, GRIET, Hyderabad from 2008 June to Oct 2013. Before that he worked as a Professor in CSE department, GRIET, Hyderabad since 2007 November. Prior to that, he worked as Asso. Prof. in VNRVJIET, Hyderabad where he joined in 1996. His total teaching experience is 23 years. His writings have appeared in numerous Professional conferences and Journals (International journals-29, national Journals-3, International conferences- 23, national conferences- 1 , Total $=\mathbf{5 6}$ ). Under his guide ship 6 Ph.D. Research Scholars got awarded (3- JNTUH \& 3-ANU). He has received seminar grants from AICTE and DST organizations. Reviewer for many International Conferences like ICACM-2011, ICACM-2013, ICRSKT, ITQM, ICCCT etc., He has also received UGC Project Grant as a Principle Investigator and AICTE project grant as Co-Principle Investigator. He is a Review Committee Member \Editorial Board member for 18 International Journals namely IJAEGT, IJAC, JDECS, IJEAT, IJAENT, etc., He was an author for few books i.e. Artificial Intelligence etc. His current research area interests include Image processing, Data Warehousing \& Mining, Spatial data mining, web mining, Text mining and Robotic area etc. He is presently guiding (supervisor \& cosupervisor level) many Ph.D. scholars at various universities namely JNTUH, JNTUK, JNTUA and ANU. He was called for around 55 AICTE sponsored \ TEQIP workshops as resource person. He is Life Member in ISTE, CSI and a member in IEEE. 